\title{
The effects of castration followed testosterone supplementation in prostatic complex of Artibeus planirostris (Chiroptera: Phyllostomidae)
}

\author{
Cíntia C.I. Puga a ${ }^{a}$ Mateus R. Beguelini ${ }^{b}$, Eliana Morielle-Versute ${ }^{c}$, Patricia S.L. Vilamaior ${ }^{a}$, \\ Sebastião R. Taboga ${ }^{a, *}$
}

a Univ. Estadual Paulista - UNESP, Department of Biology, São José do Rio Preto, São Paulo, Brazil

b Center of Biological and Health Sciences, Universidade Federal do Oeste da Bahia, UFOB, Barreiras, Bahia, Brazil

${ }^{c}$ Univ. Estadual Paulista - UNESP, Department of Zoology and Botany, São José do Rio Preto, São Paulo, Brazil

\section{A R T I C L E I N F O}

\section{Article history:}

Received 13 October 2015

Received in revised form 26 February 2016

Accepted 27 February 2016

Available online 17 March 2016

\section{Keywords:}

Bat

Castration

Hormone supplementation

Testosterone

Prostate

\begin{abstract}
A B S T R A C T
The prostatic complex (ventral and dorsal regions) of Artibeus planirostris exhibits seasonal variations throughout the year. Circulating testosterone was correlated with prostate weight, showing an increase from autumn to summer, with the highest peak in summer corresponding to the largest breeding season. This indicates that the level of serum testosterone influences variations in both testicular and prostatic weights. Serum testosterone levels seem to be closely related to the different responses of these glands throughout the year. The castration (consequent suppression of testosterone) and subsequent hormone supplementation may elucidate the relationship of these two glandular types with testosterone. Thus, the aim of this study was to evaluate the effect of castration and the testosterone supplementation in the male prostatic complex of $A$. planirostris. The results indicated that both prostatic regions were affected by the ablation of testosterone, presenting a decrease in cell proliferation and an increase in apoptosis. Similarly, the prostate was responsive to hormonal supplementation, having a recovery of the active morphophysiological pattern with testosterone supplementation. However, data have shown that the ventral region was more sensitive to changes in testosterone than the dorsal, presenting greater cell renewal.
\end{abstract}

(c) 2016 Elsevier Ltd. All rights reserved.

\section{Introduction}

The male reproductive accessory glands (RAGs) are organs that compose the male reproductive system and are of great importance for secreting products that ensure the survival, viability and motility of spermatozoa (Setchell and Breed, 2006), a fact that has a great influence on the reproductive success of mammals. Crichton and Krutzsch (2000) compiled the existing data on reproduction in bats and stated that both the anatomy and histology of their reproductive organs (testes and accessory glands) followed the mammalian pattern, with a pair of testis and epididymis and accessory glands, such as: prostate, seminal vesicles, ampullary glands and the bulbourethral glands, which may or may not be present in the reproductive system.

Studies demonstrated that the RAGs of the phyllostomid bats Artibeus planirostris (Puga et al., 2013) and Platyrrhinus lineatus

\footnotetext{
* Corresponding author at: Department of Biology, Laboratory of Microscopy and Microanalysis, University Estadual Paulista - UNESP, Rua Cristovao Colombo, 2265, Jardim Nazareth, CEP 15054000, São Jose do Rio Preto, São Paulo, Brazil.

E-mail address: taboga@ibilce.unesp.br (S.R. Taboga).
}

(Puga, 2011; Martins et al.,2015) were composed of a compact prostatic complex (PC), which had two distinct regions (ventral and dorsal) with associated paraurethral glands, and a pair of extraabdominal bulbourethral glands. The ventral region completely surrounded the urethra in P. lineatus; however, in A. planirostris, the urethra was partially exposed. On the other hand, in both species, the bulbourethral glands had similar locations and morphology.

The PC of $A$. planirostris exhibited seasonal variations throughout the year. Circulating testosterone was correlated with prostate weight, as they showed an increase from autumn to summer, with the highest peak in summer corresponding to the largest breeding season. This indicates that the level of serum testosterone influences variations in both testicular and prostatic weights (Puga et al., 2014).

Analyses of androgen receptors (AR) indicated that both regions expressed these receptors; however, the ventral region had no significant variation throughout the year, while the dorsal had the highest expression in the autumn and lowest in the summer. Data showed that the expression pattern of AR in the dorsal region was inversely correlated to the testosterone dosage, presenting a small number of AR-positive cells when the level of serum testosterone was high in summer and the reverse was seen in the autumn (Puga 


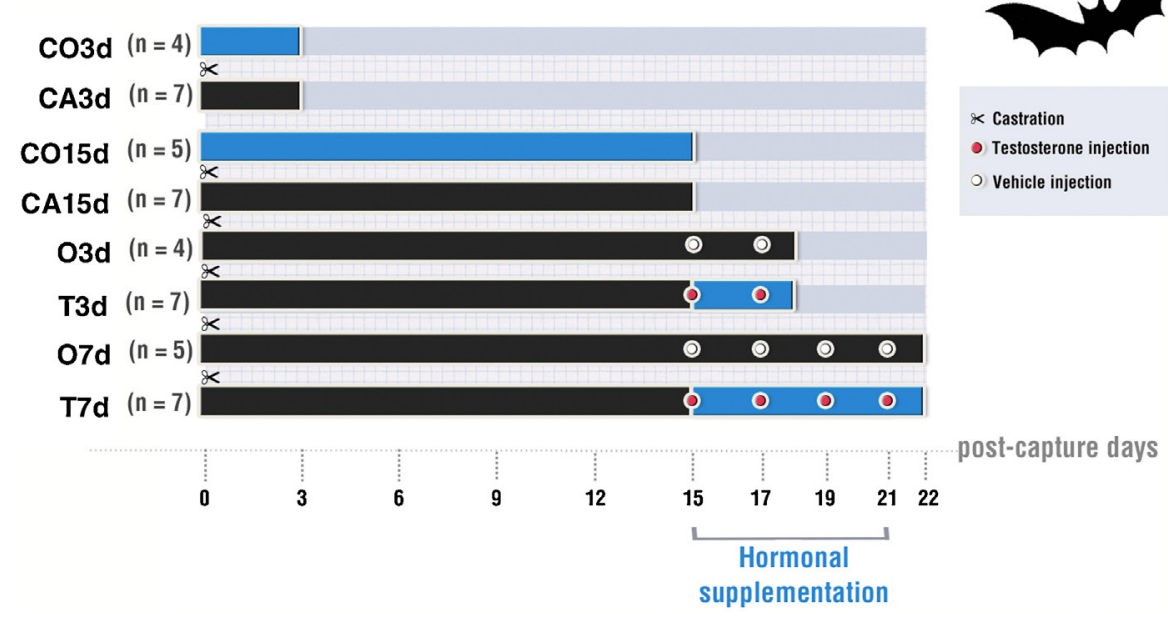

Fig. 1. Schematic representation of the experimental design used in this study.

et al., 2014). In summer, the body requires a high level of testosterone to directly stimulate the reproductive activities, but in both region of $\mathrm{PC}$, already fully developed, did not need to capture all of this testosterone, resulting in a negative feedback that reduced the synthesis of these receptors. On the other hand, in autumn, the PC, undeveloped, needs to prepare itself for the subsequent secretion of substances for the breading season; as the testosterone level was low in this period, the PC needs to increase the synthesis of AR to capture the low circulating testosterone and appropriately induce production and secretion in the prostatic epithelium (Puga et al., 2014). This study showed that the dorsal region suffered the direct influence of testosterone; however, the impact of this hormone in the ventral region was not fully elucidated. Thus, testosterone levels may be related to the different responses of these glands throughout the year.

Bats have numerous reproductive adaptations such as testicular regression, sperm storage, and big impact of seasonality on the reproductive organs that trigger seasonal changes in these organs, which are not present in laboratory animals such as rats, mice, and in humans. The impact of seasonality on species used in this study, it is clear: during the spring more than half of the secretory cells of the ventral region undergo apoptosis due to holocrine secretion process (Puga et al., 2014). Thus, this animal showed interesting from the standpoint of presenting adaptation to environmental variations, which are controlled by changes in the pattern hormonal control.

Experiments of castration (consequent suppression of testosterone) and subsequent supplementation were a general process to evaluate the impact of testosterone in different organs and types of treatments (Huttunen et al., 1981; Kiplesund et al., 1988; Carvalho et al., 1997; Shabisgh et al., 1999; Nishino et al., 2004; Góes et al., 2007). Thus, castration and subsequent testosterone supplementation may elucidate the relationship between this hormone and variation in these two prostatic regions. Therefore, the aim of this study was to evaluate the effect of castration and posterior testosterone supplementation in the two prostatic regions of A. planirostris.

\section{Materials and methods}

\subsection{Species, aging and experimental design}

The species analyzed was A. planirostris (Spix, 1823), which is an exclusively Neotropical species of phyllostomid bat that is not listed as endangered on the International Union for Conservation of Nature (IUCN) Red List of Threatened Species. The bats were aged as adults based on body weight, complete ossification of the metacarpal-phalangeal epiphyses, wear of the teeth (Knegt et al., 2005), positioning of the testes and the presence of sperm inside the testes, cauda epididymis and/or urethra (Puga et al., 2013, 2014; Beguelini et al., 2013a, 2013b, 2014a, 2014b).

A. planirostris is a wild species that is protected by federal laws in Brazil (IBAMA). Adding to these, its harem structure (with a single male mated to multiple females) means that the collection of male specimens directly influences the structure and dynamics of the populations. Thus, the number of specimens used in this study was the maximum number obtained from a balance between the minimum number required for relevant statistical analyses and the maximum number of individuals that could be collected without destroying or disrupting the colonies of bats.

Thus, 46 sexually male mature specimens were analyzed. Eight groups were formed (Fig. 1): (I) Uncastrated animals kept in captivity for 3 days (CO3d, $n=4$ ); (II) Castrated animals kept in captivity for 3 days (CA3d, $n=7$ ); (III) Uncastrated animals kept in captivity for 15 days (CO15d, $n=5$ ); (IV) Castrated animals kept in captivity for 15 days (CA15d, $n=7$ ); (V) Castrated animals kept in captivity for 15 days, thereafter treated with $0.1 \mu \mathrm{l}$ mineral oil (on alternate days) for 3 days (O3d, $n=4)$; (VI) Castrated animals kept in captivity for 15 days, thereafter treated with $0.1 \mu$ l testosterone cypionate (dose: $1 \mu \mathrm{g} / \mathrm{kg}$ on alternate days) for 3 days (T3d, $n=7$ ); (VII) Castrated animals kept in captivity for 15 days, thereafter treated with $0.1 \mu \mathrm{l}$ mineral oil (on alternate days) for 7 days (O7d, $n=5$ ) and (VIII) Castrated animals kept in captivity for 15 days, thereafter treated with $0.1 \mu$ l testosterone cypionate (dose: $1 \mu \mathrm{g} / \mathrm{kg}$ on alternate days) for 7 days (T7d, $n=7$ ).

\subsection{Study area, capture and ethics statement}

The animals were collected in the city of São José do Rio Preto, in the northwest of São Paulo State, Brazil (49W22'45", 20S49'11"), which is located $500 \mathrm{~m}$ above sea level. This is a semi-flat region, set in a degraded Cerrado biome, with meso-thermal climate with rainy summers and dry winters.

The captures were concentrated in the summer (21st December-21st March) in order to minimize variations arising from seasonality (Puga et al., 2014) and to focus on changes caused by treatments. The captures were performed at night using mist nets $(3 \mathrm{~m} \times 6 \mathrm{~m})$, which were positioned to intercept bats flying 
1-3 m above the ground. The nets were precisely placed on possible flight routes or exits from shelters.

The experimental procedures were approved by the Ethics Committee of IBILCE-UNESP (Process: 036/2010 - CEUA), and the capture of animals was authorized by the Brazilian Institute of the Environment, IBAMA (Process: 21707-1). The animals were treated according to the recommendations of the Committee on Care and Use of Laboratory Animals from the Institute of Laboratory Animal Resources, National Research Council, "Guide for the Care and Use of Laboratory Animals" (Committee on Care and Use of Laboratory Animals, 1980).

\subsection{Castration and maintenance of the animals}

To standardize the study, after capture, the animals were kept in cages $(40 \mathrm{~cm} \times 20 \mathrm{~cm} \times 20 \mathrm{~cm})$ with water and food (pieces of papaya, banana or other fruit) ad libitum, in a specific room in darkness at $25-30^{\circ} \mathrm{C}$. These conditions were only used in the period between the end of the capture and the next morning, at which point the bats were anesthetized with a mixture of ketamine (Dopalen-Vertebrands, Paulínia, SP, Brazil; $370 \mathrm{mg} / \mathrm{kg}$ ) and xylazine (Rompun - Bayer S.A., São Paulo, SP, Brazil; $16 \mathrm{mg} / \mathrm{kg}$ ), which was applied at an amount of $0.1 \mathrm{ml}$ per $50 \mathrm{~g}$ of body weight $(0.08 \mathrm{ml}$ ketamine plus $0.02 \mathrm{ml}$ of xylazine). After anesthesia, bilateral orchiectomy was performed, with a small incision in the inguinal region, in which the testicle and epididymis were removed after cutting the deferent duct. Finally the animals were sutured. After castration, the animals were maintained in the Laboratory of Microscopy and Microanalysis of the Department of Biology (IBILCE/UNESP) in a specific room in darkness at $25-30^{\circ} \mathrm{C}$. They were accommodated in cages $(100 \mathrm{~cm}$ length $\times 50 \mathrm{~cm}$ width $\times$ $30 \mathrm{~cm}$ height) dotted with grids at the superior portion to facilitate aeration, proper positioning of the animal (upside down) and feeding. Only 2 or 3 animals were placed per cage to avoid the stress of overpopulation. The animals received water ad libitum and the feeding corresponded to fresh and tender fruits (papaya, banana, etc.), which were changed every day, since it is a frugivorous species. The cages were cleaned every day, with the water exchange and the supplementation of the feed being performed simultaneously in order to cause the lowest possible stress to the animal, with these processes occurring without the direct manipulation of the animals. All animals were manipulated only for the performance of the treatments (injections of testosterone).

\subsection{Processing of the animals}

To standardize, all specimens were euthanized by deep anesthesia (mixture of ketamine and xylazine), administered subcutaneously, and positioned in dorsal decubitus on the dissection board. After the body weight was measured, blood samples were collected by endocardial puncturing. A longitudinal incision in the skin and subcutaneous tissues was performed, from the xiphoid process to the pubic symphysis, with the PC and adrenal glands removed, weighed and fixed for analysis.

All specimens are archived in the Chiroptera Collection of the Laboratory of Chiroptera at the Univ. Estadual Paulista, UNESP; Instituto de Biociências, Letras and Ciências Exatas, IBILCE.

\subsection{Serum hormone dosage}

The blood, collected by endocardial puncture, was immediately centrifuged at $1200 \mathrm{~g}$, to separate the serum, and frozen at $-80^{\circ} \mathrm{C}$ for subsequent analysis of testosterone levels. The testosterone dosages were performed by ELISA Capture/Sandwich (antibody-antigen-antibody), using specific commercial kits (Cayman Chemical Company, Ann Arbor, Michigan, USA - Item \# No.
$582701)$ of high sensitivity $(6.0 \mathrm{pg} / \mathrm{ml})$, with coefficients of variation for an inter-assay of $32.0 \mathrm{pg} / \mathrm{ml}$. Readings were taken using an Epoch $^{\mathrm{TM}}$ Multi-Volume Spectrophotometer System (BioTekInstruments, VT, USA) reader.

\subsection{Histology}

The PC was fixed by immersion in Metacarn fixative solution (methanol:chloroform:acetic acid - 6:3:1) for $3 \mathrm{~h}$ at $4{ }^{\circ} \mathrm{C}$, dehydrated in ethanol, diaphanized in xylene and embedded in paraffin (Histosec - MERK, Darmstadt, Germany). Sections of $4 \mu \mathrm{m}$ were stained with hematoxylin-eosin (HE [Ribeiro and Lima, 2000]), periodic acid-Schiff (PAS [Behmer et al., 1976]) and Picrosirius (Junqueira et al., 1979) or submitted to immunostainings. Microscopic analyses were performed using an Olympus BX60 microscope (Olympus Optical Co., Ltd., Tokyo, Japan) with coupled image analyzer (Image Pro Plus version 6.1 for Windows Copyright (C) 1993-2006 Media Cybernetics, Inc.).

\subsection{Stereological analysis and morphometry}

The following measurements were performed on cross sections of the PC (ventral and dorsal regions) using the Image Pro-PlusMedia Cybernetics, version 6.1 for Windows computer software for image analysis: the relative percentage of glandular compartments (epithelium, lumen and stroma), the epithelium height and the cell population census.

Stereology: For this analysis, 50 fields of the slides stained by HE (dorsal region) and Picrosirius (Ventral region) were randomly selected from each experimental group. The relative frequency of glandular components (epithelium, lumen and stroma) was calculated by applying an M130 multipoint test system (Weibel, 1963).

Morphometry: To measure the epithelium height, random fields were captured from each animal, with three measurements performed in each field, accumulating a total of 300 measurements for each experimental group.

The cell population census was conducted on histological sections submitted to p63 immunohistochemistry (protocol described below). For this analysis, 50 fields of the slides submitted to p63 immunohistochemistry were selected from each experimental group. In each field, the amounts of basal and other cells were measured by direct counting of nuclei.

\subsection{Immunohistochemistry and TUNEL analysis}

After microwaving for antigen retrieval, nonspecific antibody binding was blocked using $3 \%$ of bovine serum albumin prior to incubation with primary antibodies: androgen receptor (AR) - rabbit polyclonal IgG (sc-816/Santa Cruz Biotechnology, Santa Cruz, CA, USA, dilution 1:75); p63 - mouse monoclonal IgG2a (sc-25268/Santa Cruz Biotechnology, Santa Cruz, CA, USA, dilution $1: 100$ ); proliferating cell nuclear antigen (PCNA) - mouse monoclonal IgG2a (sc-56/Santa Cruz Biotechnology, Santa Cruz, CA, USA, dilution 1:100); and apoptosis (TUNEL - TdT-Fragel-Calbiochem, second manufacturer's instructions, Oncogene Research Products, Boston). The sections were then incubated with specific secondary anti-rabbit biotinylated antibodies (ABC kit, sc-2018, Santa Cruz Biothecology CA) (AR) or polymer (Post Primary Block and polymer, Novocastra, Newcastle Upon Tyne, UK; DAKO Envision ${ }^{\mathrm{TM}}+$ Dual link system-HRP, K4061) for $45 \mathrm{~min}$ at $37^{\circ} \mathrm{C}$ (p63 and PCNA). The sections were them revealed with DAB (diaminobenzidine, Sigma, St. Louis, MO) and counterstained with Harris hematoxylin. Negative controls were used, omitting the incubation step with the primary antibody or enzyme (in the case of TUNEL).

The relative percentage of positive and negative cells in the acinar epithelium was determined using measurement fields of the 
Table 1

Biometric and hormonal data in the eight experimental groups.

\begin{tabular}{|c|c|c|c|c|c|c|}
\hline \multicolumn{7}{|c|}{ Biometric and hormonal data } \\
\hline & Group & Initial weight (g) & Final weight (g) & Adrenal (mg) & Prostatic complex (mg) & Testosterone (ng/dL) \\
\hline \multirow{4}{*}{ Castration effect } & $\mathrm{CO} 3 \mathrm{~d}$ & $47.7 \pm 1.0$ & $51.2 \pm 1.7$ & $8.6 \pm 0.9$ & $64.5 \pm 19.2^{a, b}$ & $68.8 \pm 29.9^{a}$ \\
\hline & CA3d & $47.1 \pm 1.5$ & $48.7 \pm 1.5$ & $8.9 \pm 0.6$ & $70.6 \pm 8.7^{\mathrm{a}, \mathrm{c}}$ & $29.9 \pm 2.1^{\mathrm{a}}$ \\
\hline & C015d & $45.7 \pm 1.5$ & $50.2 \pm 2.2$ & $6.7 \pm 0.6$ & $77.6 \pm 14.8^{\mathrm{a}}$ & $63.5 \pm 5.0^{\mathrm{a}}$ \\
\hline & CA15d & $47.8 \pm 1.1$ & $52.2 \pm 2.6$ & $6.6 \pm 0.6$ & $26.9 \pm 2.8^{\mathrm{b}}$ & $21.7 \pm 0.9^{\mathrm{a}}$ \\
\hline \multirow[t]{4}{*}{ Supplementation effect } & O3d & $47.0 \pm 2.0$ & $52.0 \pm 1.7$ & $8.2 \pm 0.6$ & $32.2 \pm 9.3^{\mathrm{b}, \mathrm{c}, \mathrm{d}}$ & $7.2 \pm 3.5^{\mathrm{a}}$ \\
\hline & T3d & $47.3 \pm 1.5$ & $51.0 \pm 1.6$ & $7.4 \pm 0.6$ & $35.9 \pm 3.2^{\mathrm{b}}$ & $463.7 \pm 103.6^{b}$ \\
\hline & O7d & $48.5 \pm 1.5$ & $50.4 \pm 1.5$ & $7.0 \pm 0.4$ & $32.6 \pm 2.7^{\mathrm{b}}$ & $8.3 \pm 3.9^{\mathrm{a}}$ \\
\hline & T7d & $47.6 \pm 1.2$ & $48.3 \pm 1.1$ & $8.1 \pm 0.9$ & $70.9 \pm 5.8^{\mathrm{a}, \mathrm{d}}$ & $489.5 \pm 76.5^{b}$ \\
\hline
\end{tabular}

$\overline{\mathrm{a}, \mathrm{b}, \mathrm{c}}$ Different superscript letters indicate significant differences between experimental groups (ANOVA at $p<0.05$ ).

entire length of the slides. The ratio between the proliferation and cellular apoptosis of the acinar epithelium was also calculated by dividing the percentage of PCNA-positive by that of TUNEL-positive cells (\% cell PCNA-positive/\% cell TUNEL-positive).

\subsection{Statistical analysis}

All numerical data were expressed as means and standard error, and analyzed initially by analysis of variance (One-way ANOVA) and, subsequently, by a Tukey test for multiple comparisons $(p \leq 0.05=$ significant $)$, using the Statistica 7.0 program (Statsoft Inc., Tulsa, USA).

\section{Results}

\subsection{Body, adrenal and PC weights and testosterone hormone levels}

Biometric data (Table 1) showed no significant differences between the initial and final values of body and adrenal weights in all experimental groups, despite the increased weight of all animals held in captivity. The PC weights of the CO3d, CA3d and CO15d groups also did not differ statistically; however, the CA15d group had a significant reduction. The PC weights of the O3d and O7d groups had similar values to that of the CA15d group. Similarly, the T3d group did not show any significant difference when compared to the CA15d group. On the other hand, the T7d group presented an increase in PC weight, which displayed similar values to the normal pattern (control animals). These data indicated that the short-term treatments (3 days: CA3d and T3d) had weak effects on PC; however, the long-term treatments had a direct impact on PC. In the same way, they demonstrated the importance of testosterone for normal PC physiology, where its absence triggered a regression of the glandular complex and its supplementation promoted a recovery in function, observed in the increased weight.

The serum hormone dosage (Table 1) showed a decrease in the level of testosterone in the CA3d and CA15d groups when compared with the CO3d and CO15d groups, but this decrease was not statistically significant. The O3d and O7d groups showed even lower values and the groups with hormone supplementation (T3d and T7d) had high values.

\subsection{Histology, stereological and morphometric analyses}

\subsubsection{Castration effect}

The ventral region of the CO3d and CO15d groups showed normal morphology (epithelium with basal nuclei, lumen filled with globular secretion and a little of stroma - Fig. 2A, B and G, H) and the CA3d group (Fig. 2D and E) had no changes in morphology compared to these controls (Fig. 2A, B and G, H). However, the CA15d group presented a pronounced glandular regression with a large cell concentration (Fig. 2J and K), regions with cellular debris
(Fig. 2J) and changes in the glandular secretion (Fig. 2K). Similarly, the dorsal region had no morphological differences between the CO3d (Fig. 2C), CA3d (Fig. 2F) and CO15d (Fig. 2I) groups; however, the CA15d group also presented glandular regression, with increases in the stromal areas and in the epithelium height at the more peripheral regions (Fig. 2L).

Stereologically, the ventral region presented no significant difference in the amount of epithelium between groups; however, the lumen and stroma varied inversely (Fig. 4A). The lumen presented higher values in the CO3d, CA3d and CO15d groups and a significant reduction in the CA15d group, while the stroma had lower values in the CO3d, CA3d and CO15d groups and a significant increase in the CA15d group (Fig. 2J and K). Similarly, the dorsal region showed similar behavior in relation to the lumen and stromal components (Fig. 3C).

The morphometry of the dorsal region showed a small decline in the epithelium height in castrated groups (CA3d and CA15d Fig. 4E).

\subsubsection{The effect of hormone supplementation}

The ventral region of the O3d (Fig. 3A and B), T3d (Fig. 3D and E) and O7d (Fig. 3G and H) groups showed a similar morphology to the CA15d group (Fig. 2J and K), presenting pronounced glandular regression with regions indicative of a higher cell concentration, cellular debris, a change in the pattern of glandular secretion and also an increase in stromal areas. However, the long-term treatment with testosterone (T7d) showed a return to normal glandular morphology (Fig. 3J and K). Similarly, the dorsal region had no morphological differences between the O3d (Fig. 3C), T3d (Fig. 3F) and O7d (Fig. 3I) groups and the CA15d group (Fig. 2L); however, the long-term treatment with testosterone (T7d) showed a return to normal glandular morphology, with a decline in stromal areas (Fig. 3L).

Stereologically, the ventral region presented no significant difference in the amount of epithelium between groups; however, the lumen and stroma varied inversely (Fig. 4B). The stroma was higher than the lumen in the 03d, T3d and 07d groups; however, the T7d group had a significant increase in the lumen and a consequent significant decrease in the stroma (Fig. 4B). Unlike the ventral region, the dorsal region showed a significant increase in the amount of epithelium in the groups treated with testosterone (T3d and T7d Fig. 4D). However, it had a similar behavior in relation to the lumen and stromal components (Fig. 4D).

The morphometry of the dorsal region showed an increase in the epithelium height in groups treated with testosterone (T3d and T7d - Fig. 4F).

\subsection{Cell population census}

\subsubsection{Ventral region}

The cell population census revealed a significant increase in the number of basal and the other cells in the CA15d group (Fig. 5A and 


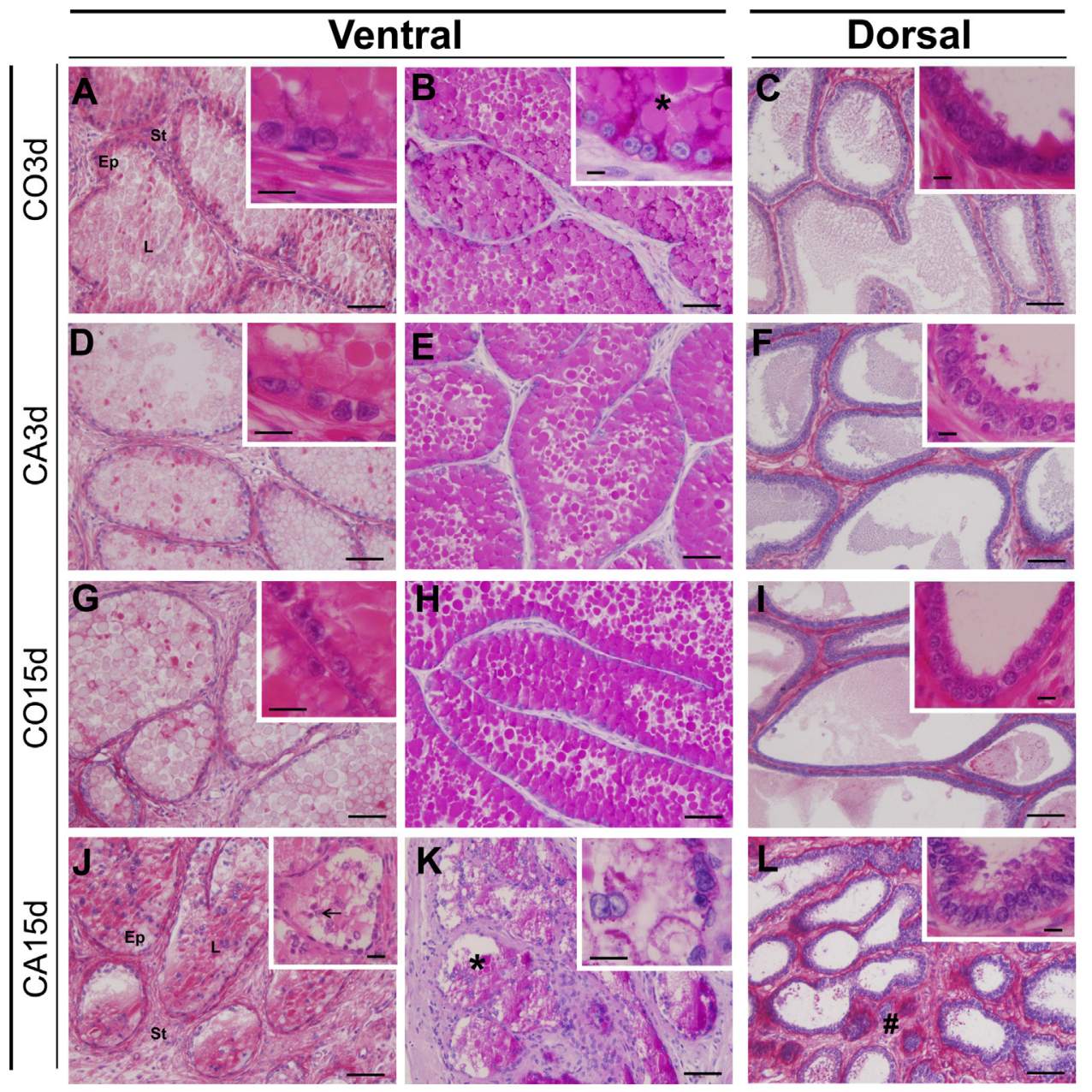

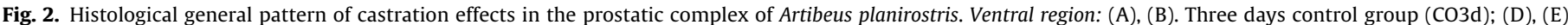

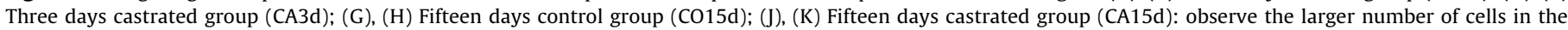

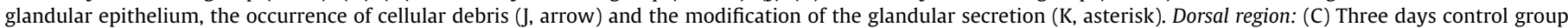

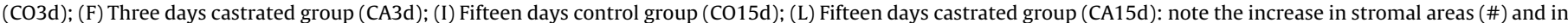

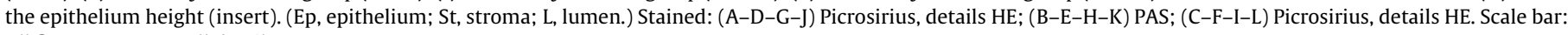
All figures $=50 \mu \mathrm{m}$; all details $=10 \mu \mathrm{m}$.

D), in relation to the CO3d, CA3d and CO15d groups (Fig. 5A and C). This number remained high in the $\mathrm{O} 3 \mathrm{~d}, \mathrm{O} 7 \mathrm{~d}$ and T3d groups (Fig. 5B and $\mathrm{E}$ ), and returned to normal in the T7d group (Fig. 5B and F).

\subsubsection{Dorsal region}

The dorsal region presented a significant increase in the number of basal and other cells in the CA15d group (Fig. $5 \mathrm{G}$ and J) in relation to the CO3d, CA3d and CO15d groups (Fig. 5G and I). This number remained high in the O3d, O7d and T3d groups (Fig. 5H and $\mathrm{K}$ ), and was normal in the T7d group (Fig. $5 \mathrm{H}$ and $\mathrm{L}$ ).

\subsubsection{Index p63-positive cell/p63-negative cell}

Dividing the number of basal cells by the other cells enabled the development of an index, which indicates that the CA15d group has a large number of basal cells, which was not found in the other groups (CA3d, CO3d and CO15d, Table in Fig. 5).

The groups with hormonal supplementation had similar patterns between the groups. The dorsal region of the T7d group showed a similar index to the control group on 3 and 15 days; however, the ventral region, even with supplementation, continued to have a higher index than the CA15d or control groups (Table in Fig. 5).

\subsection{Immunohistochemistry}

\subsubsection{Androgen receptor (AR)}

The AR immunohistochemistry showed, in both regions, a small decrease in AR-positive cells in the CA3d and CA15d groups in relation to the control groups (CO3d and $\mathrm{CO} 15 \mathrm{~d}$ ); however, this decrease was not statistically significant (Ventral: Fig. 6A-E; Dorsal: Fig. 6G-K). On the other hand, in the hormone supplementation groups, there was a significant decrease in AR-positive cells in the O7d group (Fig. 6F and L).

\subsubsection{Cell proliferation (PCNA)}

PCNA showed a significant decrease of cell proliferation in the ventral region of the CA15d group (Fig. 7A and D) when compared with the CO3d (Fig. 7C), CO15d and CA3d groups.

Groups submitted to hormone supplementation [T3d (Fig. 7B and $\mathrm{G}-\mathrm{H}$ ) and $\mathrm{T} 7 \mathrm{~d}$ ] showed a recovery in cell proliferation, especially in the first days of the application of the hormone. This result indicates that the glandular remodeling is mediated by testosterone and this remodeling has a peak in the first application of the hormone (T3d, Fig. $7 \mathrm{G}$ and $\mathrm{H}$ ).

The dorsal region showed no significant differences in the number of PCNA-positive cells in any of the studied groups (Fig. 7I-M). 


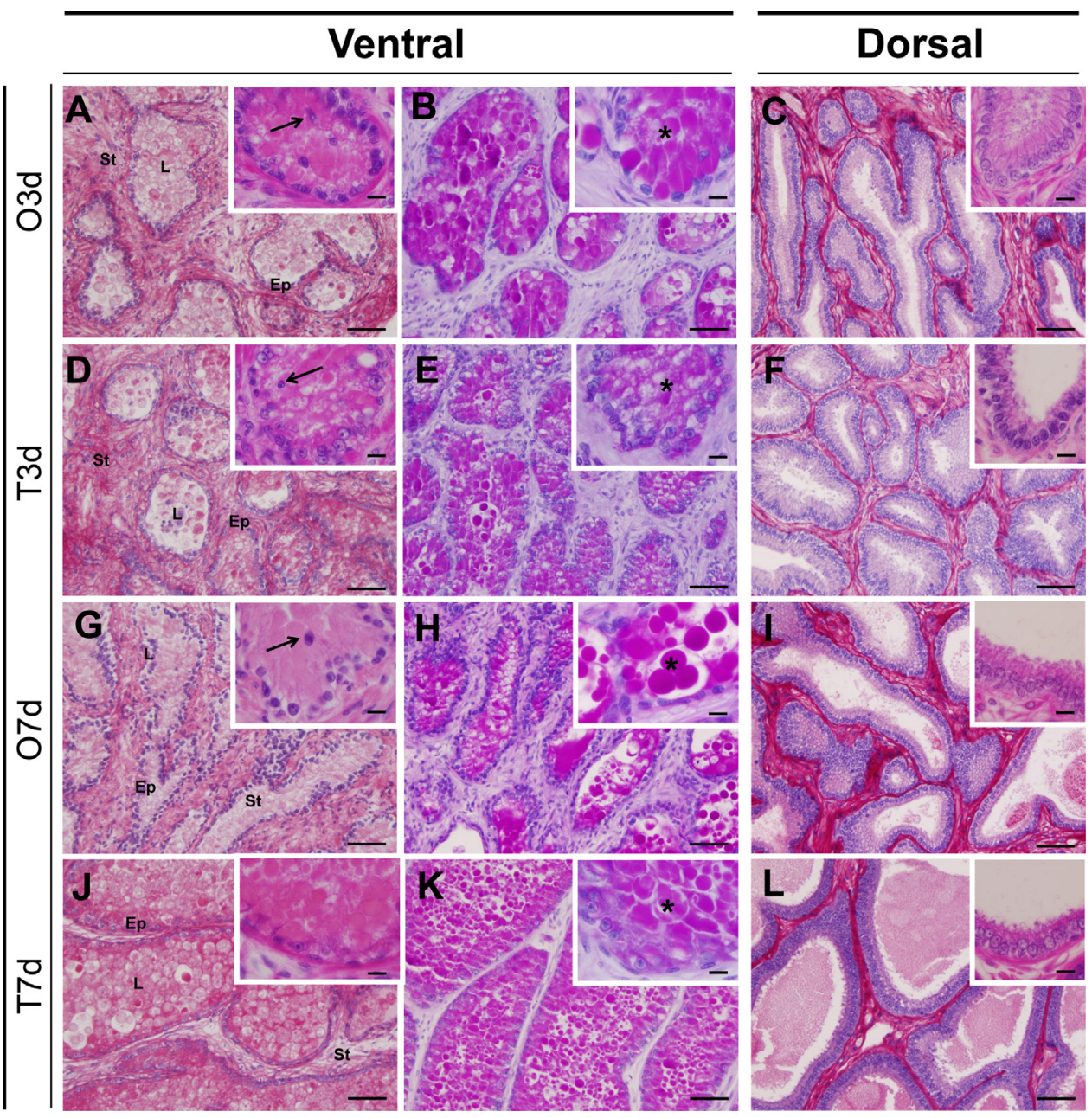

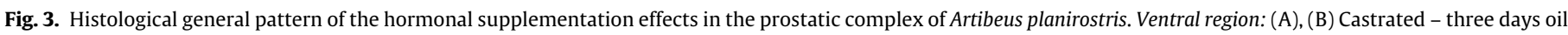

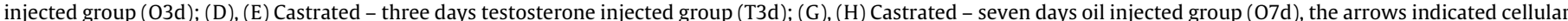

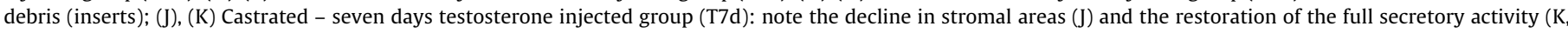

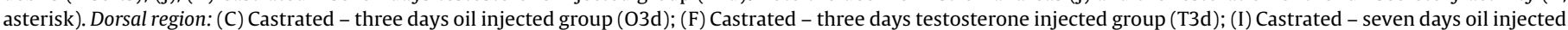

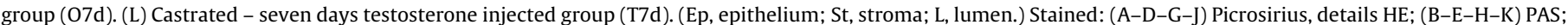
(C-F-I-L) Picrosirius, details HE. Scale bar: All figures $=50 \mu \mathrm{m}$; all details $=10 \mu \mathrm{m}$.

\subsubsection{Apoptosis (TUNEL)}

The ventral region showed a significant increase in apoptosis in the CA15d group (Fig. 8A and D) when compared with the CO3d (Fig. 8A and C), CA3d and CO15d groups (Fig. 8A). O3d and O7d (Fig. 8B and E) had high rates of cell death, which were slightly lower than that of the CA15d group. The testosterone supplementation (T3d and T7d groups) caused a decline in cellular apoptosis (Fig. 8B and F).

Similarly, the dorsal region also showed a significant increase in apoptosis in the CA15d group (Fig. 8G and J) when compared with the CO3d, CA3d (Fig. 8G and I) and CO15d groups (Fig. 8G). O3d (Fig. $8 \mathrm{H}$ and $\mathrm{K}$ ) and $\mathrm{O7d}$ (Fig. $8 \mathrm{H}$ and $\mathrm{L}$ ) had high rates of cell death, but they were lower than that of the CA15d group, and the T3d and T7d groups had a decline in cellular apoptosis (Fig. 8H); however, the values did not differ significantly.

\subsubsection{Rate of cell proliferation (PCNA/TUNEL)}

The PCNA/TUNEL ratio showed similar results for both regions (Fig. 8): a decline in castrated groups (CA15D, O3D and O7d) compared to control groups (CO3d and $\mathrm{CO} 15 \mathrm{~d}$ ) and an increase in the groups treated with testosterone (T3d and T7d) compared to castrated groups (O3d and O7d).

\section{Discussion}

Aumuller and Seitz (1990) confirmed that the depletion of androgens in castration caused atrophy of the androgen-responsive organs, with a remarkable reduction in size and weight. In our work, the reduction in hormone levels caused changes in glandular morphology, such as increases in the cellular debris, percentage of stroma and modifications in their secretory pattern. The authors, together with Risbridger et al. (2001), postulated that this morphology returned to the normal pattern when testosterone was injected, since this hormone regenerated the prostatic epithelium, restoring the function and number of normal cells. Despite the fact that the decrease in the levels of serum testosterone in castrated groups (CA3d and CA15d) was not statistically significant, several similar morphological and physiological changes in the prostatic complex were related to castration, as was a return to the normal pattern in groups with hormone supplementation (T3d and T7d). Thus, the reduction in circulating testosterone (castration) caused a decrease in prostatic weight (Ca15d), which returned to the initial state with hormone supplementation (T7d), showing that the testosterone actively regulated the prostatic morphophysiology in A. planirostris, a pattern also observed in seasonal analyzes (Puga et al., 2014). 


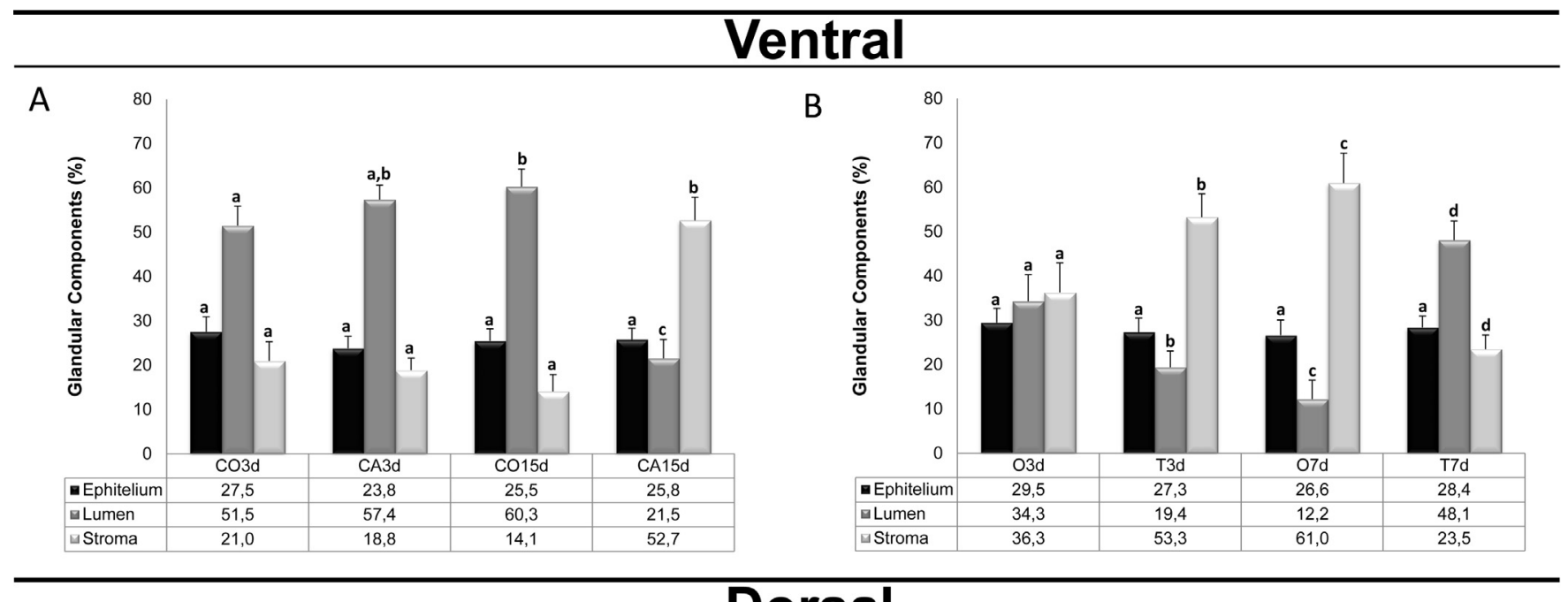

\section{Dorsal}

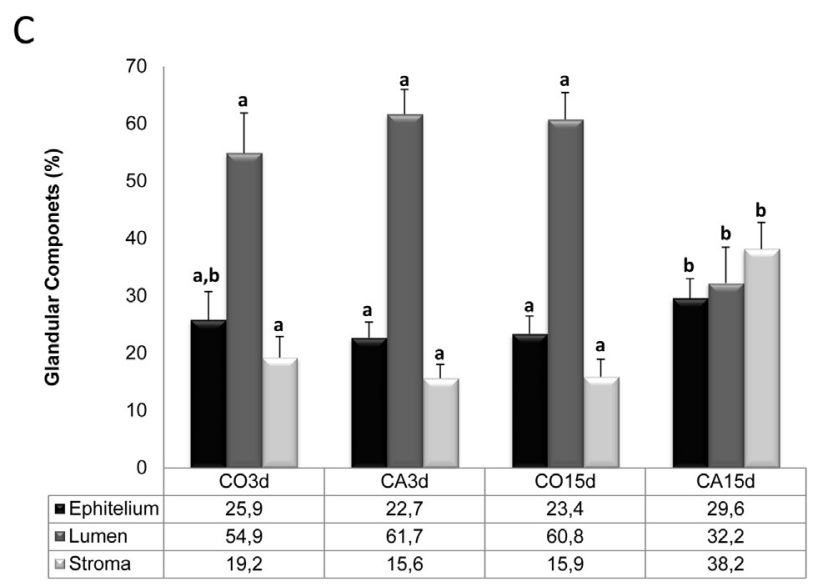

$\mathrm{E}$

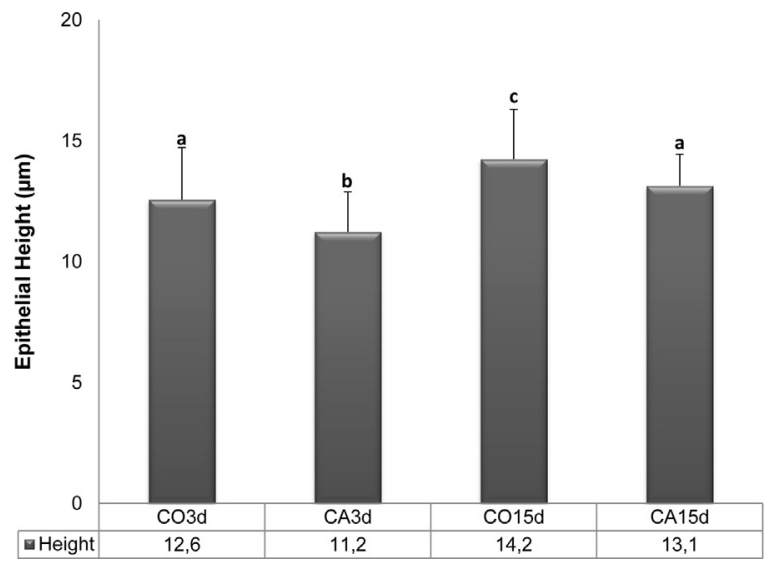

D

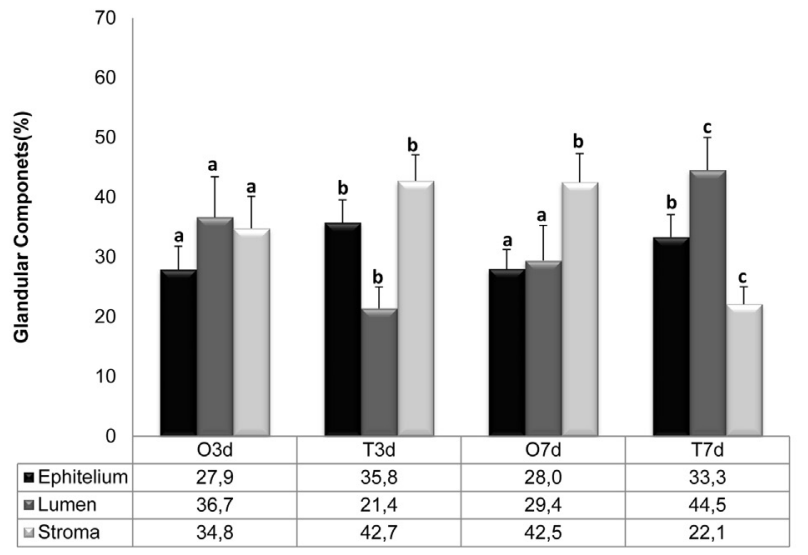

$\mathrm{F}$

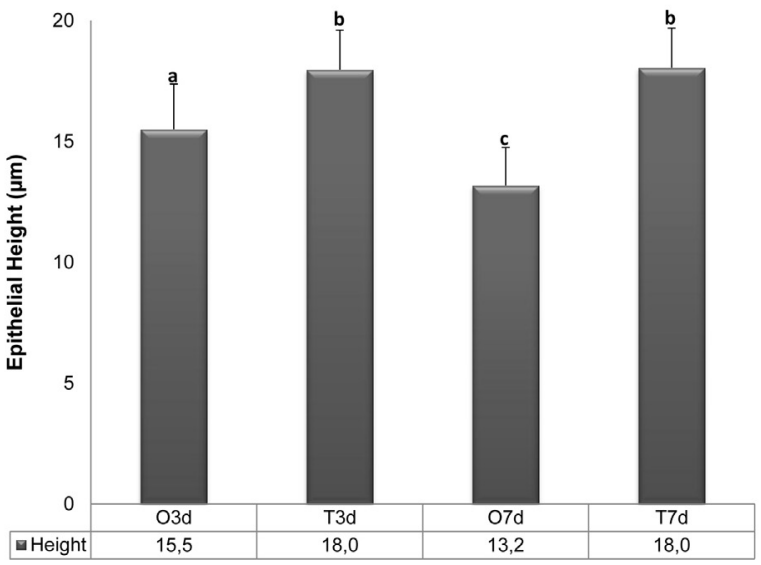

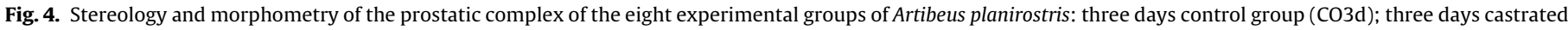

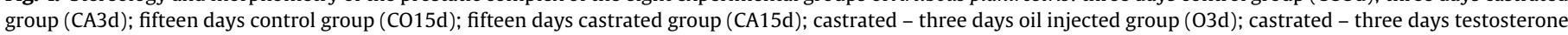

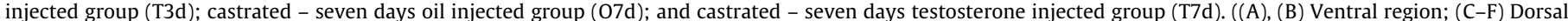

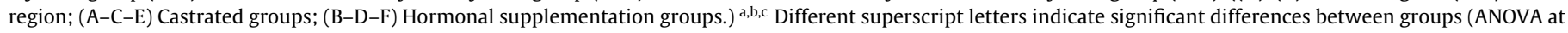
$p<0.05)$.

Stereologically, we observed that the CA3d group maintained the morphology of the control groups (CO3d and CO15d), which indicates that both prostatic regions take longer than three days to respond to decreased levels of testosterone. Rochel-Maia et al. (2011) observed a similar pattern in gerbils, indicating significant differences in these parameters only in the 21 day castrated group; this pattern was also observed in the present study, where an increase in the stroma and the lumen regression occurred after 15 days of castration, with this morphology remaining altered in the groups treated with oil (O3D and O7d). The data also indicated that short-term treatments (injection of testosterone) have little effect on both prostatic regions, with the gland presenting patterns 

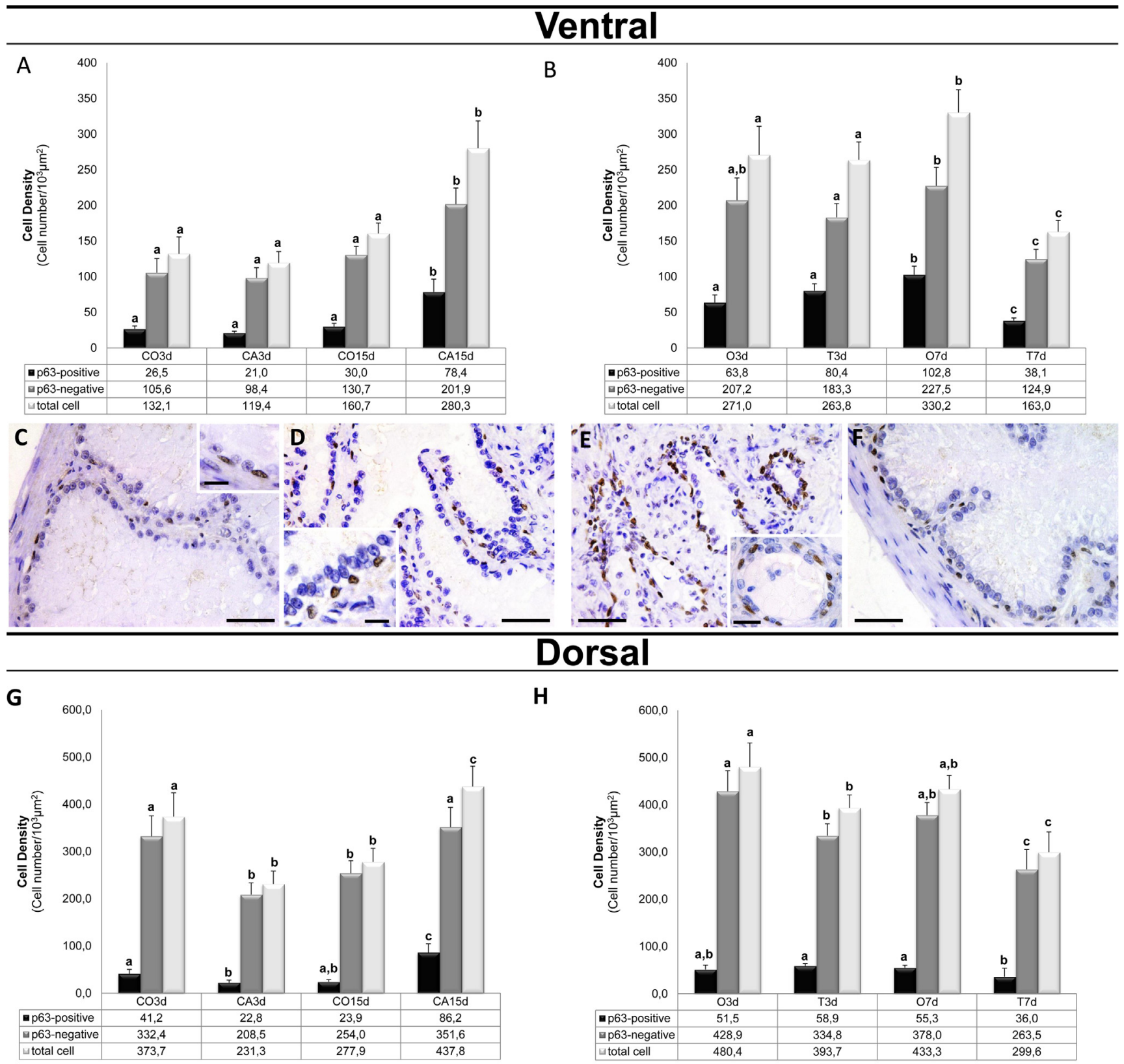

H
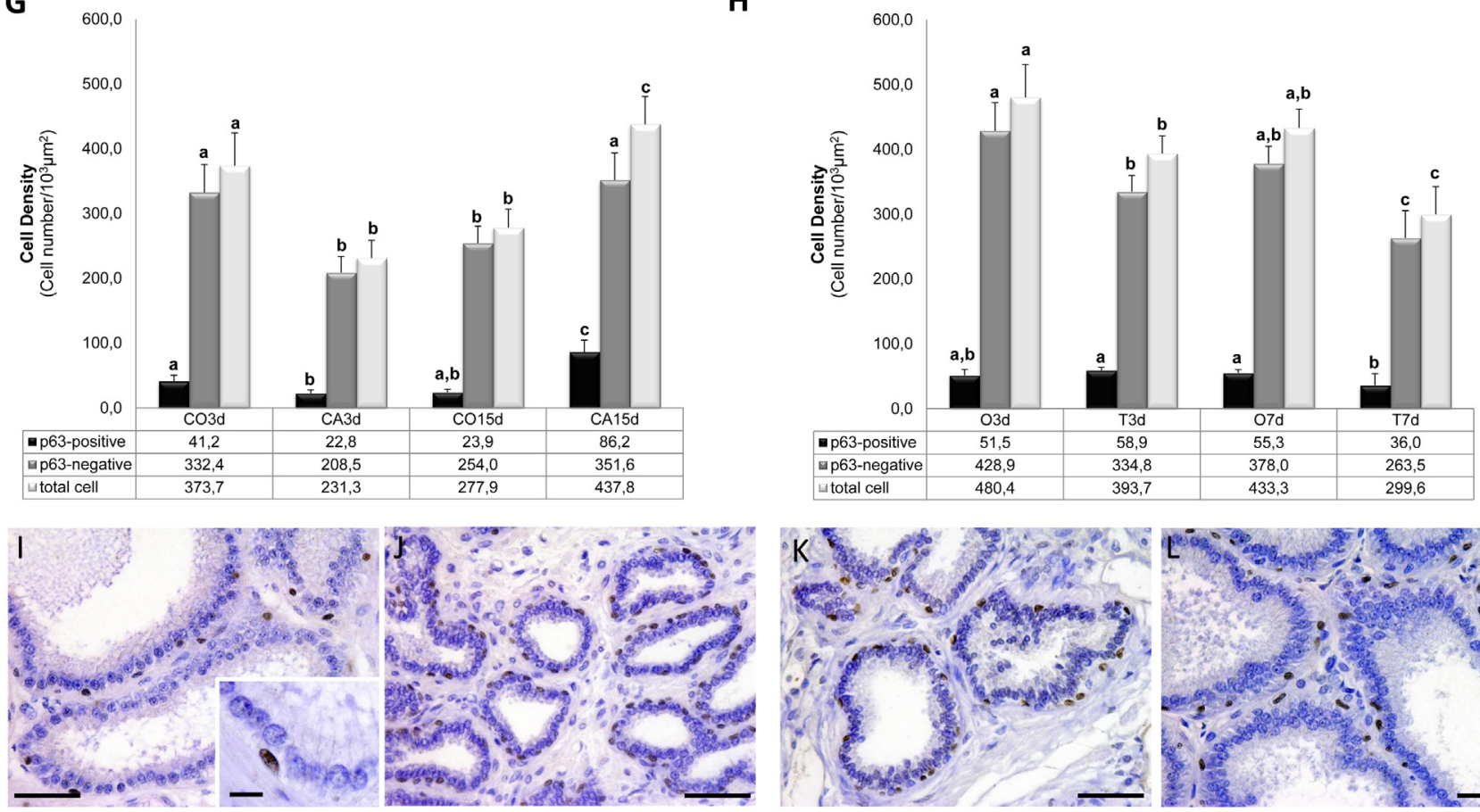

Index p63-positive/p63-negative

\begin{tabular}{lllllllll}
\hline Groups & CO3d & CA3d & CO15d & CA15d & O3d & T3d & O7d & T7d \\
\hline Ventral & $0.27 \pm 0.04^{\mathrm{a}, \mathrm{e}}$ & $0.23 \pm 0.03^{\mathrm{a}}$ & $0.23 \pm 0.03^{\mathrm{a}}$ & $0.37 \pm 0.06^{\mathrm{b}, \mathrm{c}, \mathrm{f}}$ & $0.31 \pm 0.04^{\mathrm{a}, \mathrm{c}, \mathrm{h}}$ & $0.45 \pm 0.05^{\mathrm{b}, \mathrm{g}}$ & $0.47 \pm 0.06^{\mathrm{d}, \mathrm{g}}$ & $0.32 \pm 0.04^{\mathrm{e}, \mathrm{f}, \mathrm{h}}$ \\
Dorsal & $0.12 \pm 0.02^{\mathrm{a}}$ & $0.11 \pm 0.02^{\mathrm{a}}$ & $0.10 \pm 0.02^{\mathrm{a}}$ & $0.30 \pm 0.10^{\mathrm{b}}$ & $0.12 \pm 0.02^{\mathrm{a}}$ & $0.18 \pm 0.02^{\mathrm{a}}$ & $0.15 \pm 0.02^{\mathrm{a}}$ & $0.13 \pm 0.02^{\mathrm{a}}$
\end{tabular}

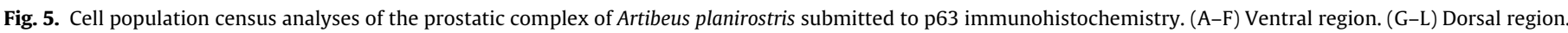

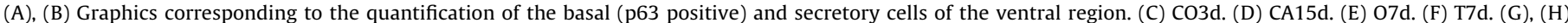

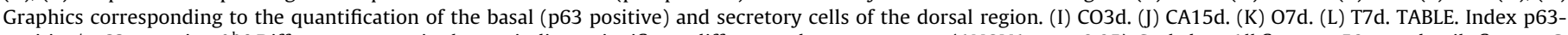

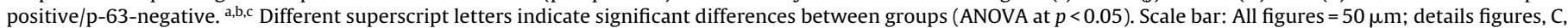
$\mathrm{D}$ and $\mathrm{I}=10 \mu \mathrm{m}$; detail figure $\mathrm{E}=20 \mu \mathrm{m}$. 


\section{Ventral}
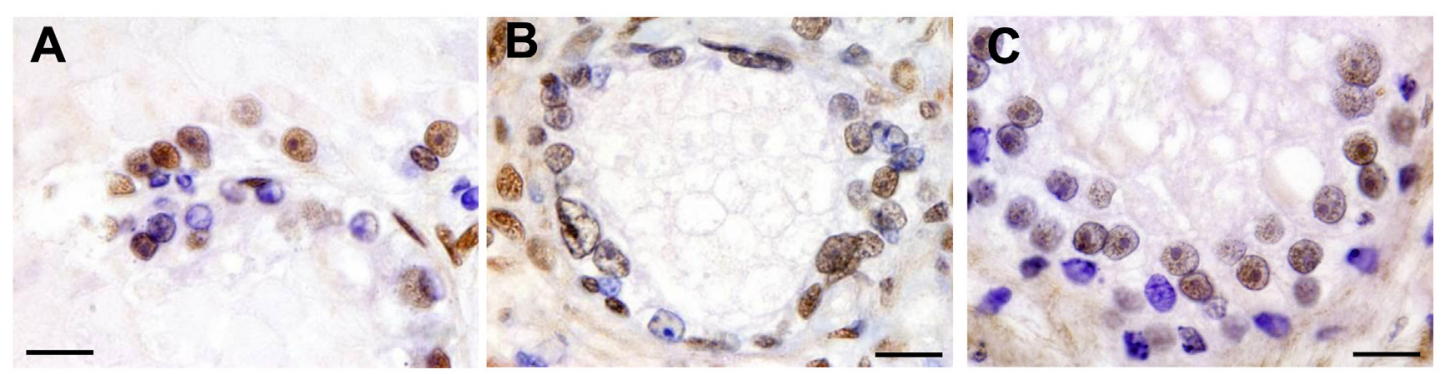

D

E

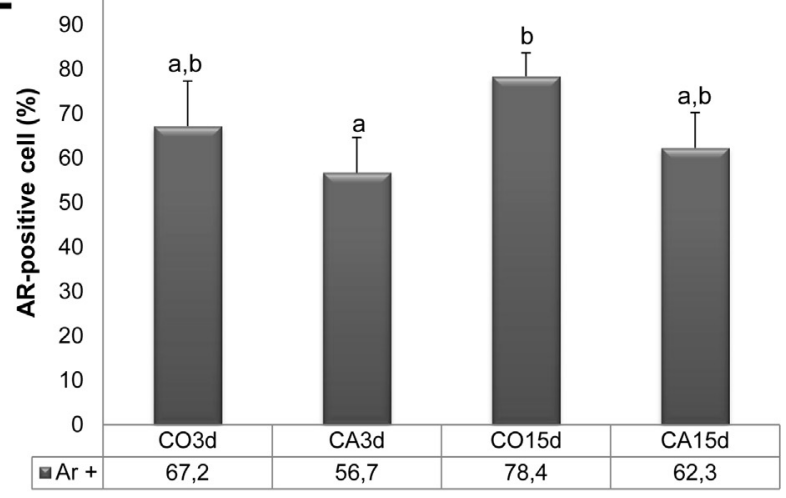

$\mathbf{F}$

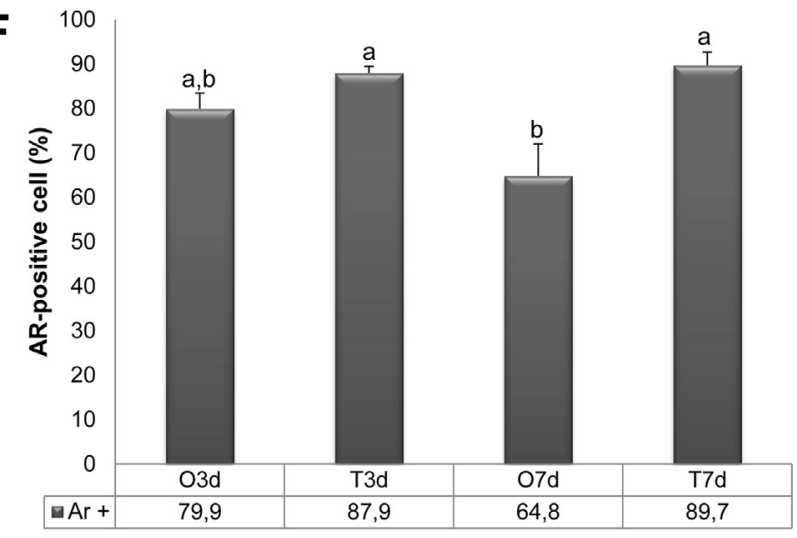

\section{Dorsal}
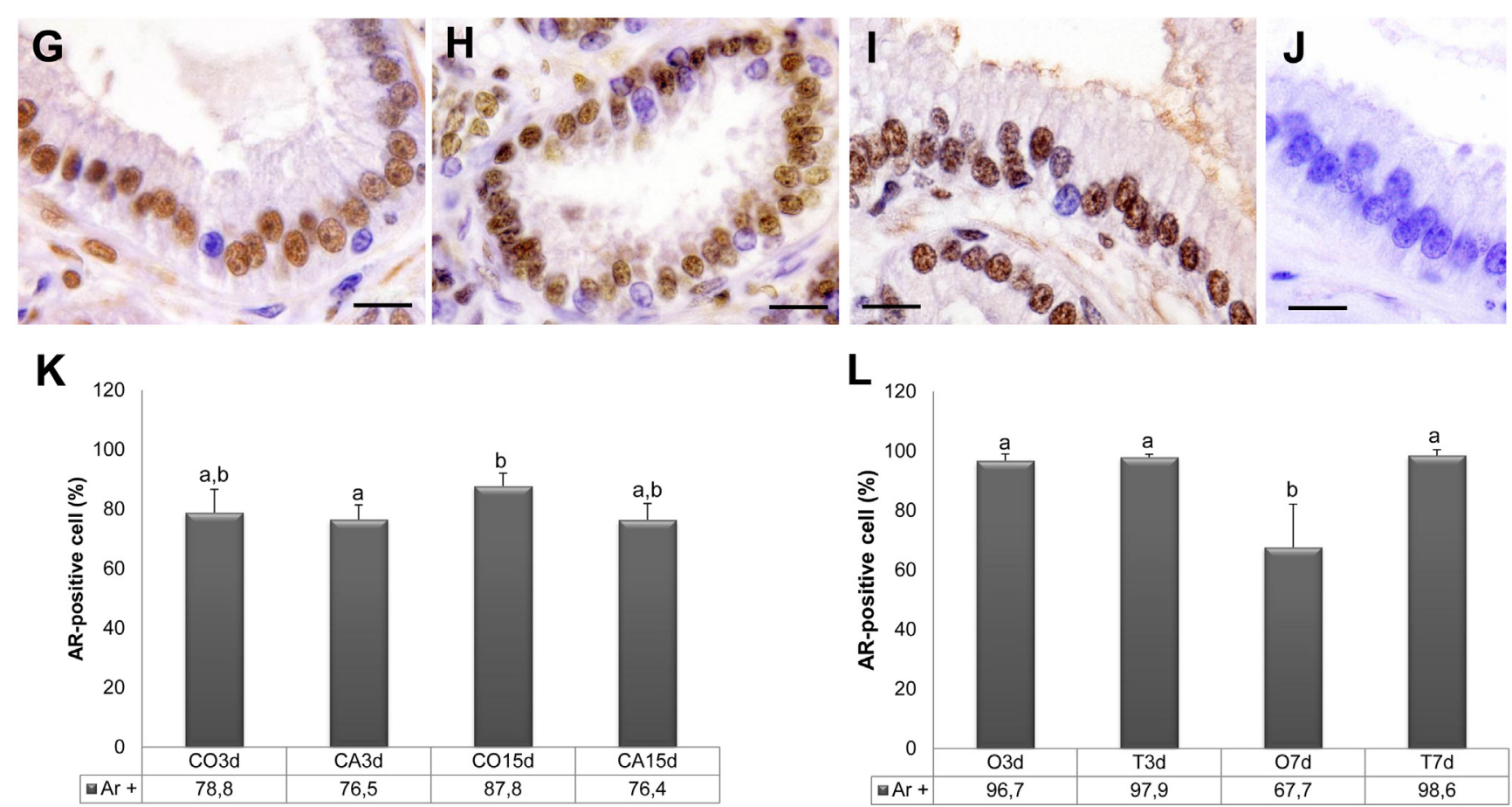

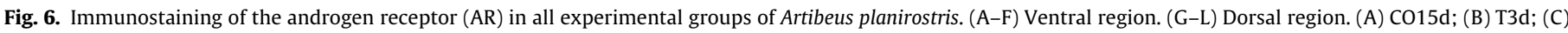

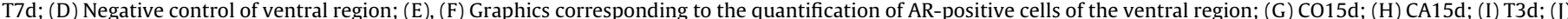

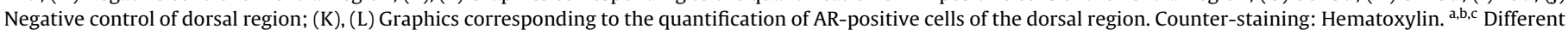
superscript letters indicate significant differences between groups (ANOVA at $p<0.05$ ). Scale bar: All figures $=10 \mu \mathrm{m}$.

of reactivation only after a longer period (T7d) of testosterone administration.

The cell population census indicated an increase in the density of basal and other cells in groups with reduced testosterone (castrated and oil injected groups) as expected due glandular regression and acini atrophy. Despite this, the Index p63-positive/p63-negative, which is not affected by a decrease in the glandular area, furthermore showed the increase in the index in long-term castrated 

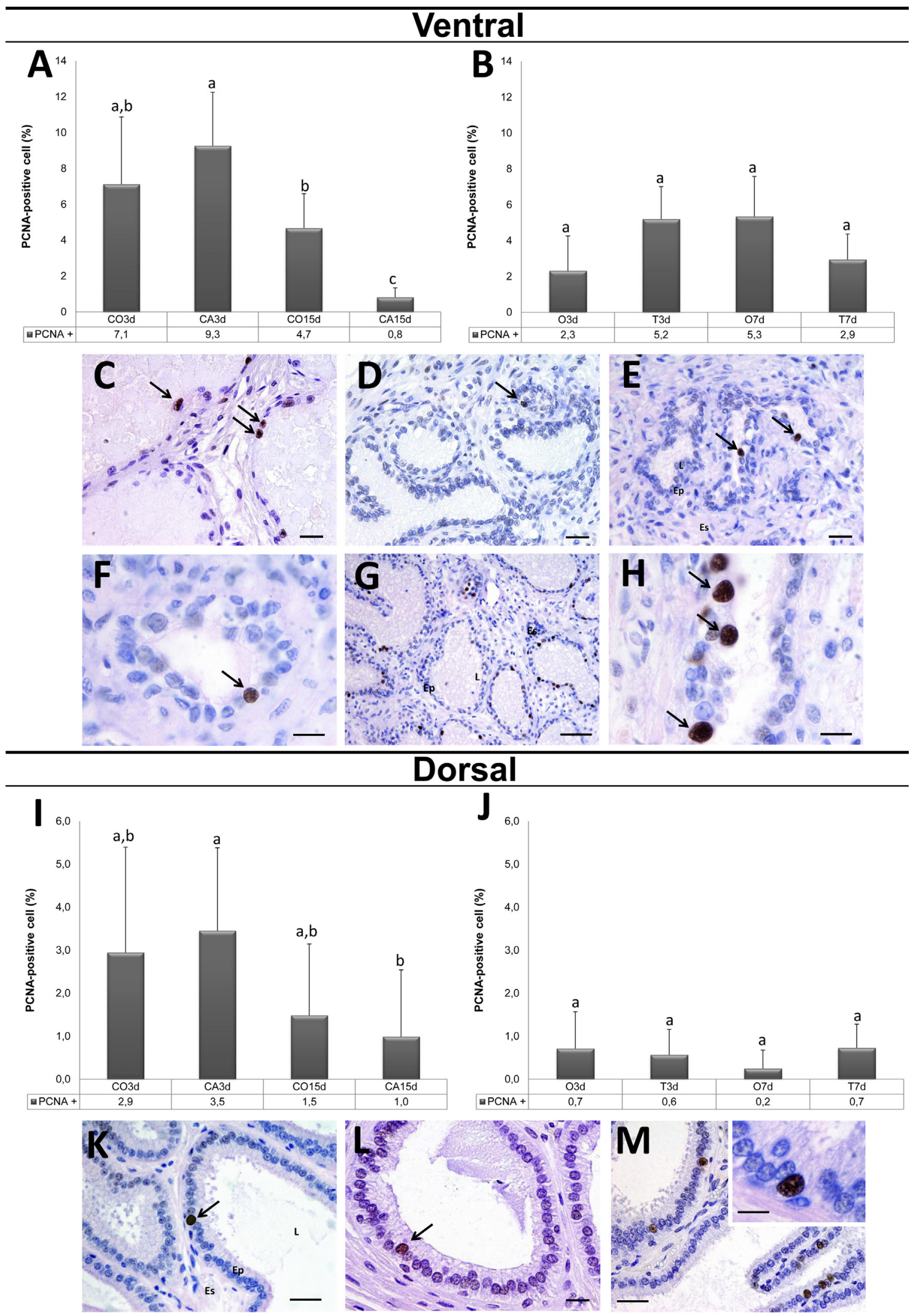

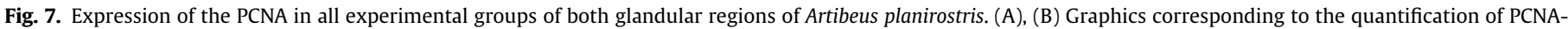

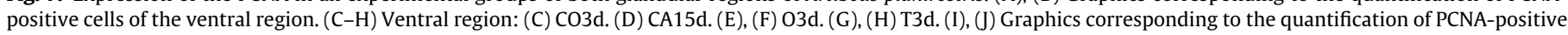

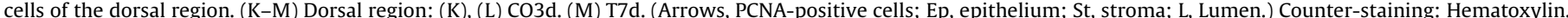

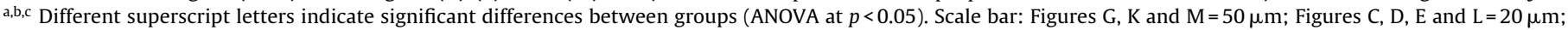
Figures. $\mathrm{F}, \mathrm{H}$ and detail $\mathrm{M}=10 \mu \mathrm{m}$. 


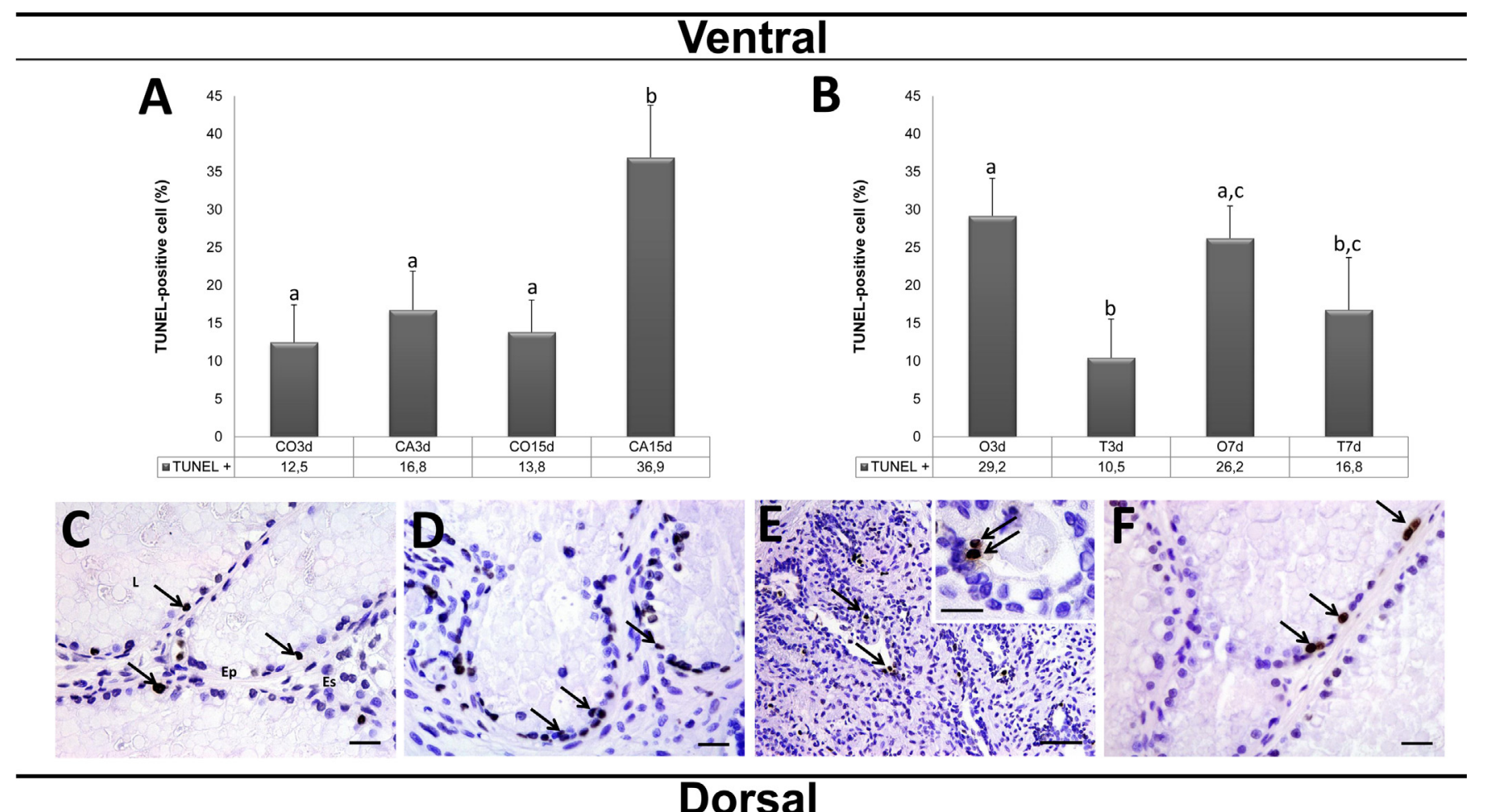

\section{Dorsal}
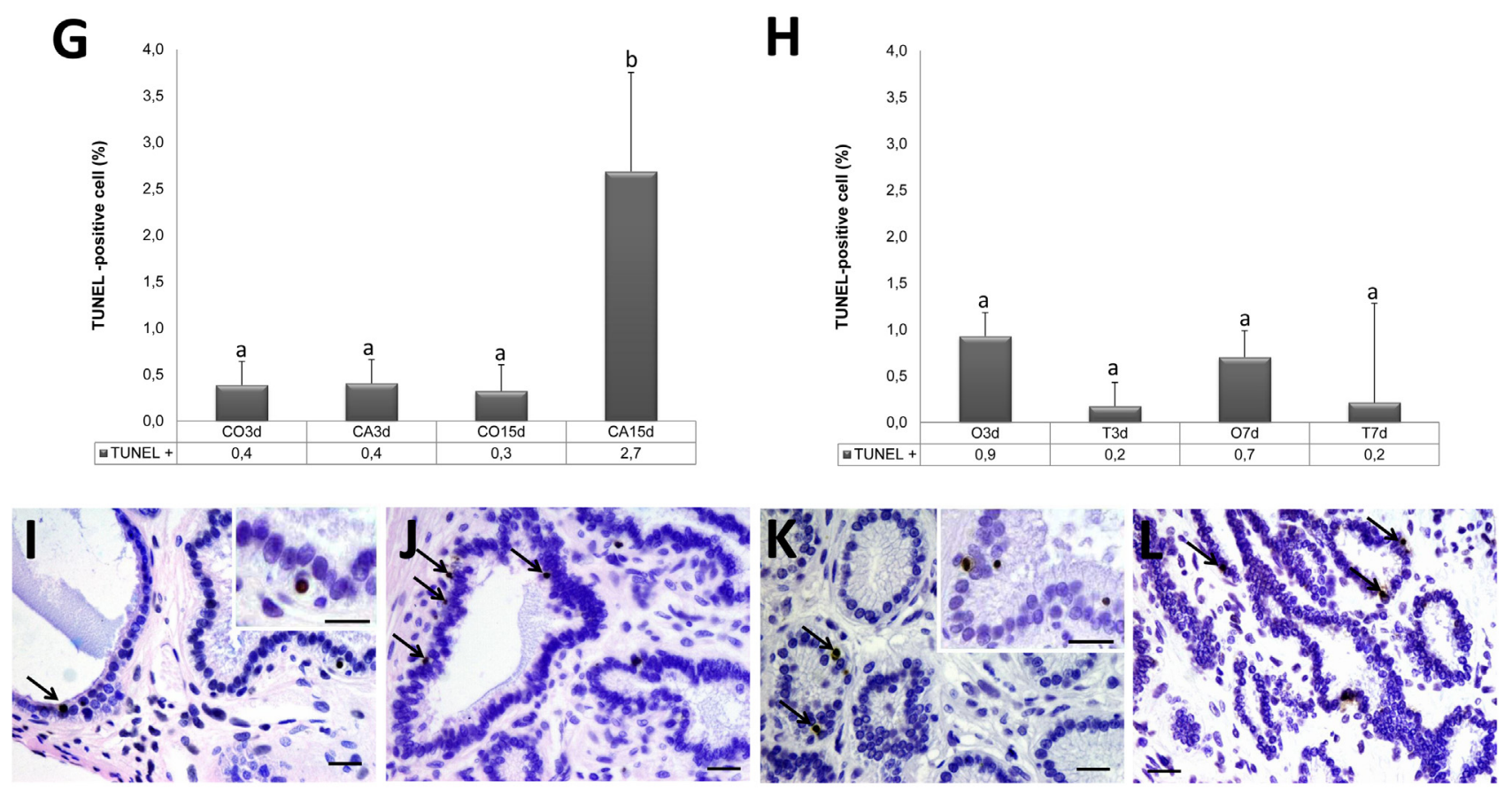

\section{Index PCNA/TUNEL}

\begin{tabular}{lllllllll}
\hline Groups & CO3d & CA3d & C015d & CA15d & O3d & T3d & 07d & T7d \\
\hline Ventral & 0.57 & 0.55 & 0.34 & 0.02 & 0.08 & 0.50 & 0.20 & 0.18 \\
Dorsal & 7.59 & 8.49 & 4.60 & 0.37 & 0.77 & 3.26 & 0.35 & 3.38 \\
\hline
\end{tabular}

Fig. 8. Apoptotic cell (TUNEL) in all experimental groups of both glandular regions of Artibeus planirostris. (A), (B) Graphics corresponding to the quantification of TUNELpositive cells of the ventral region. (C-F) Ventral region. (C) CO3d. (D) CA15d. (E) O7d. (F) T7d. (G), (H) Graphics corresponding to the quantification of TUNEL-positive cells of the dorsal region. (I-L) Dorsal region. (I) CA3d. (J) CA15d. (K) O3d. (L) 07d. (Arrows, TUNEL-positive cells; Ep, epithelium; St, stroma; L, lumen.) Counter-staining: Hematoxylin. TABLE. Index PCNA/TUNEL. a,b,c Different superscript letters indicate significant differences between groups (ANOVA at $p<0.05$ ). Scale bar: Figure $\mathrm{E}=50 \mu \mathrm{m}$; Figures C, D, F, I, J, K and L=20 $\mathrm{m}$; detail Figures $\mathrm{E}$ and $\mathrm{K}=10 \mu \mathrm{m}$. 
groups (CA15D, O3d and O7d), indicated the marked cell death and loss of secretory cells.

The data showed that the AR expression was directly related to the levels of serum testosterone, where it decline in castrated and increased in treated groups, as described in the literature (Cordeiro et al., 2008). However, Puga et al. (2014) identified that the dorsal region of $A$. planirostris had fewer AR-positive cells in the season with a higher level of testosterone in the blood. This divergence can be explained by the situation to which each study was subjected. In the first case, the AR-positive cells increased with testosterone level, because this gland was atrophied and needed to return to the normal activity pattern due to testosterone stimulation. In the second case, the gland was already morphologically active, so it did not need to increase the expression of AR.

Similarly, there was a decline in cell proliferation in the CA15d group and a tendency to increase in the hormone supplementation groups, which indicated that testosterone was related to the rate of cell proliferation. However, when there was supplementation, the proliferation remained low, indicating that the testosterone was not the principal factor causing cell proliferation and the consequent glandular reestablishment. The data showed that the factor which most influenced the glandular restructuring was cell death, as it significantly increased in the castrated group (CA15d) along with a decline of cell proliferation, causing glandular regression. With hormone supplementation, cell death declined, which allowed a return of glandular activity, even in a low proliferation state.

Cunha et al. (1996) affirmed that the morphology and function of the adult prostate tissue were maintained by the stimulation of the androgenic hormones, which regulated a balance between a very low proliferation rate and cell death. Pereira et al. (2006), studying the rat ventral prostate, also observed a decline in the rate of cell proliferation in castrated animals. In addition, Puga et al. (2014) had observed that the decrease in cellular proliferation in animals collected in the fall was related to the decline in testosterone levels. Therefore, we can conclude that, in A. planirostris, testosterone levels were more closely related to maintaining a low mortality rate than to promoting cellular proliferation.

Kyprianou and Issacs (1988) claimed that surgical castration caused an abrupt and significant decrease in serum androgen levels, also causing a reduction in the prostate, as this is controlled by the level of androgens. This reduction induces apoptosis in prostatic secretory cells. Although our hormone data did not show significant differences, we still observed a decline in testosterone, which directly influenced the prostatic morphology of the CA15d group.

In the castrated group observed a higher rate of cellular death, which decreases in the castrated groups for prolonged periods $(03 \mathrm{~d}$ and $07 d$ ), a fact that indicate that the bats have a response to the lack of testosterone slower than in rodents, in which the apoptosis process began after $24 \mathrm{~h}$ of castration, increased significantly between 48 and $72 \mathrm{~h}$ and declined thereafter (Shabisgh et al., 1999).

The decline in cellular apoptosis, observed in the ventral region of the hormone supplementation groups, was in agreement with that postulated by Puga et al. (2014), who showed that there was a decline in cellular apoptosis in the summer, which was the season with the highest hormone level. On the other hand, the dorsal region of the CA15d group showed an increase in apoptotic cells when compared to the control groups (CO3d and CO15d), which was clearly explained by the surgical castration that caused an abrupt and significant decrease in serum androgen levels and also a reduction in blood flow to the prostate, thus inducing apoptosis in prostatic secretory cells (Kyprianou and Issacs, 1988).

Our data indicated that both prostatic regions were responsive to the ablation and supplementation of testosterone; however, the ventral region was more sensitive to changes in testosterone than the dorsal, having a higher cell renewal, which may be explained by its holocrine pattern. The prostatic regulation by testosterone seemed to be more closely related to maintaining a low mortality rate than to the promotion of cellular proliferation, with an accentuated decrease in proliferation and an increase in apoptosis in the castrated groups and inhibition of apoptosis and only a small increase in proliferation in the groups treated with testosterone.

Knowing that testosterone acts on AR stimulating the cells to produce and secrete, and which can be converted by 5-alpha reductase to estradiol (E2), which acts via estrogen receptors (ER), as well as to the homeostasis of prostate these two hormones must be balanced, in the correct proportions, we can infer that: (1) Testosterone and AR are related to cellular secretion process, as in the castrated group, testosterone decline is accompanied by a AR decline, as well as cellular secretion. (2) The increase of cell death observed in castrated groups is related to unbalance between testosterone and estradiol, as well as increased estrogen receptor beta type (ER $\beta$ ). (3) The return of glandular activity testosterone works by stimulating the AR (secretory process) as well as its excess is converted to estradiol, which will stimulate the alpha type estrogen receptors $(E R \alpha)$, resulting in high rate of proliferation observed. Therefore, testosterone is important in prostate cell homeostasis, but for understanding these processes, it is necessary to correlate with other hormones and prostate components.

\section{Funding}

This work was supported by the São Paulo State Research Foundation - FAPESP [2011/01323-2 to C.C.I.P.; 2012/09194-0 to M.R.B.]; and the Brazilian National Research and Development Council (CNPq) [300163/2008-8 and 301596/2011-5 to SRT.

\section{Acknowledgements}

Technical help from Luiz Roberto Falleiros Junior is highly appreciated. Also greatly appreciate the collaboration of the Carolina Frandsen Pereira da Costa in the scheme of the experimental design.

\section{References}

Aumuller, G., Seitz, J., 1990. Protein secretion and secretory process in male accessory sex glands. Int. Ver. Cytol. 121, 127-231.

Beguelini, M.R., Bueno, L.M., Caun, D.L., Taboga, S.R., Morielle-Versute, E., 2014a. Ultrastructure of spermatogenesis in the short-tailed fruit bat, Carollia perspicillata (Chiroptera: Phyllostomidae: Carollinae). J. Morphol. 275 (1), 111-123.

Beguelini, M.R., Falleiros, L.R., Góes, R.M., Rahal, P., Morielle-Versute, E., Taboga, S.R., 2014b. Differential expression of aromatase, estrogen receptor alpha and $17 \beta-H S D$ associated with the processes of total testicular regression and recrudescence in the bat Myotis nigricans (Chiroptera: Vespertilionidae). Gen. Comp. Endocrinol. 201, 53-64.

Beguelini, M.R., Puga, C.C., Martins, F.F., Betoli, A.H., Taboga, S.R., Morielle-Versute, E., 2013a. Morphological variation of primary reproductive structures in males of five families of neotropical bats. Anat. Rec. (Hoboken) 296 (1), 156-167.

Beguelini, M.R., Puga, C.C., Taboga, S.R., Morielle-Versute, E., 2013b. Annual reproductive cycle of males of the flat-faced fruit-eating bat, Artibeus planirostris (Chiroptera: Phyllostomidae). Gen. Comp. Endocrinol. 185, 80-89.

Behmer, O.A., Tolosa, E.M.C., Freitas-Neto, A.G., 1976. Manual de técnicas para histologia normal e patológica. EDART, Editora da Universidade de São Paulo, São Paulo, 241p.

Carvalho, H.F., Vilamaior, P.S.L., Taboga, S.R., 1997. Elastic system of the rat ventral prostate and its modifications following orchiectomy. Prostate 32, 27-34.

Cordeiro, R.S., Scarano, W.R., Campos, S.G.P., Santos, F.C.A., Vilamaior, P.S.L., Góes, R.M., Taboga, S.R., 2008. Androgen receptor in the Mongolian gerbil ventral prostate: evaluation during different phases of postnatal development and following androgen blockage. Micron 39, 1312-1324.

Crichton, E.G., Krutzsch, P.H., 2000. Reproductive Biology of Bats. Academic Press, London.

Cunha, G.R., Donjacour, A.A., Cooke, P.S., Mee, S., Bigsy, R.M., Higgins, S.J., Sugimura, Y., 1996. The endocrinology and developmental biology of the prostate. Endocr. Rev. 8, 338-362.

Góes, R.M., Zanetoni, C., Tomiosso, T.C., Ribeiro, D.L., Taboga, S.R., 2007. Surgical and chemical castration induce differential histological response in prostate lobes of Mongolian gerbil. Micron 38 (3), 231-236. 
Huttunen, E., Romppanen, T., Helminen, H.J., 1981. A histoquantitative study on the effects of castration on the rat ventral prostate lobe. J. Anat. 3 , 357-370.

Junqueira, L.C.U., Bignolas, G., Brentani, R., 1979. Picrosirius staining plus polarization microscopy, specific method of collagen detection in tissue section. J. Histochem. 11, 447-455.

Kiplesund, K.M., Halgunset, J., Fjosne, H.E., Sunde, A., 1988. Light microscopic morphometric analysis of castration effects in the different lobes of the rat prostate. Prostate 13, 221-232.

Knegt, L.V., Silva, J.A., Moreira, E.C., Sales, G.L., 2005. Bats found in the city of Belo Horizonte, MG, 1999-2003. Arq. Bras. Med. Vet. Zootec. 57 576-583.

Kyprianou, N., Issacs, J.T., 1988. Activation of programmed cell death in the rat ventral prostate after castration. Endocrinology 122, 552-562.

Martins, F.F., Puga, C.C., Beguelini, M.R., Morielle-Versute, E., Vilamaior, P.S., Taboga, S.R., 2015. Comparative analysis of the male reproductive accessory glands of bat species from the five Brazilian subfamilies of the family Phyllostomidae (Chiroptera). J Morphol. 276 (4), 470-480.

Nishino, T., Wedel, T., Schmitt, O., Bühlmeyer, K., Schönfelder, M., Hirtreiter, C., Schulz, T., Kühnel, W., Michna, H., 2004. Androgen-dependent morphology of prostates and seminal vesicles in the Hershberger assay: evaluation of immunohistochemical and morphometric parameters. Ann. Anat. 186, 247-253.

Pereira, S., Martinez, M., Martinez, F.E., Júnior, W.M., 2006. Repercussions of castration and vasectomy on the ductal system of the rat ventral prostate. Cell Biol. Int. 30 (2), 169-174

Puga, C.C.I., (Dissertação (Mestrado)) 2011. Morfofisiologia das glândulas reprodutivas acessórias masculinas de morcegos: estudo nas espécies Artibeus planirostris e Platyrrhinus lineatus (Chiroptera: Phyllostomidae). Universidade Estadual Paulista, Instituto de Biociências, Letras e Ciências Exatas, São José do Rio Preto, $129 \mathrm{f}$.
Puga, C.C.I., Beguelini, M.R., Martins, F.F., Morielle-Versute, E., Faleiros Jr., L.R., Morielle-Versute, E., Vilamaior, P.S., Taboga, S.R., 2014. Seasonal changes in the prostatic complex of Artibeus planirostris (Chiroptera: Phyllostomidae). Gen. Comp. Endocrinol. 197, 33-42.

Puga, C.C.I., Beguelini, M.R., Negrin, A.C., Christante, C.M., Morielle-Versute, E., Vilamaior, P.S., Taboga, S.R., 2013. Structure, histochemistry and ultrastructure of the male reproductive accessory glands in the Neotropical flat-faced fruit-eating bat, Artibeus planirostris (Chiroptera: Phyllostomidae). Reprod. Fertil. Dev. 25, 558-569.

Ribeiro, M.G., Lima, S.R., 2000. Iniciação às técnicas de preparação de material para o estudo e pesquisa em morfologia. SEGRAC - Editora e Gráfica Limitada, Belo Horizonte.

Risbridger, G.P., Wang, H., Frydenberg, M., Cunha, G., 2001. The metaplastic effects of estrogen on mouse prostate epithelium: proliferation of cells with basal cell phenotype. Endocrinology 142, 2443-2450.

Rochel-Maia, S.S., Santos, F.C., Vilamaior, P.S., Justulin, L.A., Felisbino, S.L., 2011 MMP-2 and TIMP-2 in the prostates of male and female Mongolian gerbils: effects of hormonal manipulation. Histol. Histopathol. 26 (11), 1423-1434.

Setchell, B.P., Breed, W.G., 2006. Anatomy, vasculature, and innervation of the male reproductive tract. In: Neill, J.D. (Ed.), Knobil and Neill's Physiology of Reproduction., 3rd ed. Elsevier, New York, pp. 771-808.

Shabisgh, A., Tanji, N., D’Agati, V., Burchardt, M., Rubin, M., Goluboff, E.T., Heitjan, D., Kiss, A., Buttyan, R., 1999. Early effects of castration on the vascular system of the rat ventral prostate gland. Endocrinology 140, 1920-1932.

Spix, J.B., 1823. Simiarum et Vespertilionum Brasiliensium Species Novae: ou histoire naturelle des espèces nouvelles de singes et de chauve-souris observées et recueillies pendant le voyage dans l'intérieur du Brésil execute par ordre de S.M. le Roi de Bavière dans les années 1817, 1819, 1818, 1820. Francisci Seraphici Hubschmanni, Monaco.

Weibel, E.R., 1963. Principles and methods for the morphometric study of the lung and other organs. Lab. Invest. 12, 131-155. 